\title{
Quality Control of Honey Using New Generation Infrared Spectrometers
}

\author{
Huseyin Ayvaz \\ Department of Food Engineering, Canakkale Onsekiz Mart University, 17020 Canakkale, Turkey
}

\begin{tabular}{l}
\hline A R T I C L E I N F O \\
Research Article \\
Received 02 March 2017 \\
Accepted 17 March 2017 \\
\hline
\end{tabular}

Keywords:

Honey

Infrared

Portable spectrometer

Handheld spectrometer

Chemometrics

*Corresponding Author:

E-mail: huseyinayvaz@comu.edu.tr

\begin{abstract}
A B S T R A C T
The objective of this study was to develop a rapid infrared technique to determine 10 key quality parameters (sucrose, glucose, fructose, reducing sugar, 5-HMF, ${ }^{\circ}$ Brix, moisture content, water activity, $\mathrm{pH}$ and free acidity) in honey by using new generation portable and handheld devices. The composition of honey samples $(n=59)$ collected from different parts of Turkey was analyzed by using established reference methods, giving wide range of concentrations for each parameter. The levels of sucrose and 5-HMF in some samples were above the established regulatory limits (Codex Alimentarius and European Union standards), indicating possible adulteration or process and storage abuse. Spectra were collected by using portable Fourier-Transformed infrared (FTIR) and handheld NIR (Near Infrared) spectrometers. Partial least squares regression (PLSR) approach was used to correlate the spectral features with compositional reference values, giving strong linear correlation coefficients and standard errors of prediction. Although both systems performed similarly, portable FTIR system was superior in predictions of sucrose, 5HMF and free acidity while portable NIR system performed noticeably better for ${ }^{\circ}$ Brix and moisture content. The data indicates that all of the 10 parameters can be measured within the minutes using both systems, providing reliable screening capabilities, flexibility and the potential for in-field applications.
\end{abstract}

\section{Introduction}

Honey, which has been used as a food and medicine since ancient times contains mainly carbohydrates and other minor constituents including proteins, amino acids, lipids, organic acids, minerals and vitamins (White, 1975). It is a naturally sweet food produced by the Apis mellifera bees, which collect the plant nectars, secretions, or secretions of insects feeding on these parts, and then produce the honey after a series of specific treatments. Honeys show structural differences depending on the region where it is produced, climatic conditions, bee type, vegetation of nectar, storage conditions and the presence of any adulteration during its production if there is any (Cozzolino et al., 2011).

Due to not only its health benefits for the consumers but also for its economic value for the producers, honey is a very important natural product, whose commercial value is constantly growing. Increasing economic value plays a crucial role in determination of real quality control criteria and supplying better quality and healthier products to the consumers (Cabanero et al., 2006). Analytically controlled quality of honey is important to meet the consumer expectation against to commercial speculations (Mendes et al., 1998). However, in determination of quality control of honey, evaluating one single parameter is not sufficient and many measurements under melissopalynological, physical and chemical analyses would be needed.

With its geographical and climatic conditions, Turkey is suitable for beekeeping and honey production in three seasons of the year and it hosted about 6.8 million hives and 105.7 thousand tons honey production for 2016 (TUIK, 2016). On the world market, Turkey ranks second behind China in honey production and exports, according to data from the year of 2015 (FAOSTAT, 2016). Additionally, most of the variety of flowers planted by pollen present in the world can also be found in Turkey.

The studies conducted on honey up to today usually have focused on determination of geographical and botanical origins, quality control and adulterations using traditional methods (Arvanitoyannis et al., 2005). However, analytical methods utilized in these studies are lengthy and they require time consuming and complex sample preparation procedures, toxic chemicals and skilled labors to conduct all these analyses. Handling each analysis individually also increases time, required sample amount and therefore the expenses needed to complete the analyses (Cozzolino et al., 2011). Hence, today's methods are unable to meet the increasing demands and provide inexpensive solutions (Garcia-Alvarez et al., 2000). Because of potential mislabeling and adulteration risks, 
regulatory agencies and industry have promoted research to find new, simple and economical methods for the determination of honey quality (Ruiz-Matute et al., 2007).

One appealing option is infrared spectroscopy because it provides rapid information about the food components and requires either minimum or no sample preparation. Applications of infrared spectroscopy include quality control and food safety providing unique information related to their biochemical make-up. There have been some studies in the literature regarding the use of infrared spectroscopy for honey analysis (Cozzolino et al., 2011) but only benchtop systems were employed in these studies requiring a physical laboratory. In recent years, new generation of portable, handheld and micro devices have been manufactured taking advantage of miniaturization of interferometers and detectors and have found applications in pharma, food and defense fields. These devices can produce spectral quality equivalent to their benchtop counterparts and they provide the flexibility of being carried to factories, farmers and farms (Ayvaz and Rodriguez-Saona, 2015). These systems have been recently used for the determination of acrylamide in potato chips, quality of butters (Pujolras et al., 2015) and cornmeal (Ayvaz et al., 2015a), acrylamide precursors in raw potatoes (Ayvaz et al., 2015b), nutritional traits of potato breeding lines (Ayvaz et al., 2016a) and quality traits of tomato juice (Ayvaz et al., 2016b).

The objective was to evaluate the capabilities of portable infrared and handheld NIR devices combined with supervised pattern recognition techniques for multicomponent analysis of honey samples. To best of my knowledge, this study is the first attempt at utilizing portable mid-IR and handheld near IR devices in honey analysis and provides a comprehensive study of honey samples in Turkey.

\section{Materials and Methods}

\section{Honey Samples and Sample Preparation}

In this work, 59 honey samples ranging from multifloral flower honeys to honeydew honeys were collected from local beekeepers and markets in Turkey. The samples were stored in dark in closed test tubes in refrigerator until further analyses. The samples were heated in a water bath (Model 2837, Thermo Fisher Scientific, Marietta, $\mathrm{OH}, \mathrm{USA}$ ) at maximum of $45^{\circ} \mathrm{C}$ for 15 minutes to liquefy and avoid the crystals. The samples then were waited to cool down to the room temperature before the infrared spectra collection.

\section{Reference Analyses}

Sugars: Sucrose, glucose and fructose levels of honey samples were determined using an HPLC (High Performance Liquid Chromatography) method modified from Bogdanov and Baumann (1988). Briefly, $1 \mathrm{~g}$ of honey sample was weighted into a test tube and $10 \mathrm{~mL}$ of distilled water at $40^{\circ} \mathrm{C}$ was added. The tubes were then closed and placed in a water bath at $40^{\circ} \mathrm{C}$ for 15 minutes. The mixture was then stirred and $0.45 \mu \mathrm{m}$ nylon disc filter was used to remove the particles. Then the filtrate was transferred into $1.5 \mathrm{ml}$ glass vials for HPLC analysis. The chromatographic system used was a Shimadzu UFLC (Shimadzu, Columbia, MD) equipped with dual pumps (LC-6AD), auto-sampler (SIL-20AHT), a column oven (CTO-20A), refractive index detector (RID-10A) and model data station (LC-20AT). For separation of sucrose, glucose and fructose, a Phenomenex RCM column ( $5 \mu \mathrm{m}$, 300 mm x 7.8 mm; GL Sciences, Torrence, Calif., USA) was used. For isocratic separation of the sugars, HPLC grade water was used as mobile phase at flow rate of 1 $\mathrm{mL} / \mathrm{min}$. Column temperature was $80^{\circ} \mathrm{C}$ and $20 \mu \mathrm{L}$ of the extract was injected for each sample. A standard curve was developed for each sugar at different concentrations ranging from 0.78 to $50 \mathrm{mg} / \mathrm{mL}$ using the sugar standards with $>99 \%$ purity. The analysis of the chromatograms was made using LC Solutions software (version 3.0, Shimadzu, Columbia, MD). Reducing sugar levels were calculated by adding the calculated glucose and fructose concentrations. Sugar analysis was done in triplicate for each sample.

5-hydroxymethylfurfural (5-HMF): For determination of 5-HMF content in honey samples, the method from Jeuring and Kuppers (1980) with slight modifications was followed. About $1 \mathrm{~g}$ sample was weighed in a $15 \mathrm{ml}$ test tube and diluted with $10 \mathrm{~mL}$ of pure water, stirred for a few minutes, filtered using a $0.45 \mu \mathrm{L}$ pore sized filter and transferred to $1.5 \mathrm{~mL}$ vials for analysis. HPLC separations were performed on an Agilent system (CA, United States) consisting of a pump (Agilent G1311A, United States), a photodiode array detector (Agilent G1315B, United States), a column oven (Agilent G1316A, United States), an auto sampler (Agilent G1313A, United States) and data station (Agilent G1315B, United States). A Symmetry $C_{18}$ column $(3.5 \mu \mathrm{m}, 150 \mathrm{~mm}$ x $4.6 \mathrm{~mm}$, Waters Corp., Milford, MA, USA) with a guard column $(4.6 \times 22 \mathrm{~mm}$; Waters Corp., Milford, MA) was used for separation at $25^{\circ} \mathrm{C}$. The samples were separated using ultra-pure water: methanol $(90: 10 \mathrm{v} / \mathrm{v})(1 \%$ acetic acid) mixture at $1 \mathrm{~mL} / \mathrm{min}$ isocratic flow rate. Twenty $\mu \mathrm{L}$ was injected for each sample and 5-HMF was detected at 285 $\mathrm{nm}$. The analysis was performed in triplicate for each sample.

\section{${ }^{\circ}$ Brix}

Soluble solid ( ${ }^{\circ}$ Brix) content of honey samples was determined using Abbe-type digital refractometer (10480 ABBE Mark II Refractometer, Reichert Scientific Instruments, NY, USA) (Bhandari et al., 1999). The analysis was performed in duplicate for each sample.

\section{Moisture Content}

Moisture content of honey samples was determined according to AOAC Official Method (969.38B, 1996) (AOAC, 1996) with the principle of refractometer reading of honey at $20^{\circ} \mathrm{C}$. For this purpose, sufficient amount of honey was placed into digital refractometer's sampling area and refractive index was read. Then, using Wedmore's table, moisture content (\%) of honey samples were determined. The analysis was performed in duplicate for each sample. 
Water activity $\left(a_{w}\right)$

Using a dew point measuring instrument (AQUA LAB, Decagon, Pullman, WA, USA) at $25^{\circ} \mathrm{C}$, water activity $\left(\mathrm{a}_{\mathrm{w}}\right)$ levels of the samples were measured. The instrument was calibrated with different saturated salt solutions ( $\mathrm{a}_{\mathrm{w}}$ of 0.250 and 0.750 ) prior to analysis. The analysis was performed in duplicate for each sample.

\section{$p H$}

For $\mathrm{pH}$ measurements of the samples, a $10 \%(\mathrm{w} / \mathrm{v})$ solution of honey in distilled water was prepared and used. The analysis was performed in triplicate for each sample.

\section{Free Acidity}

Acidity levels of the honey samples were determined by a titrimetric method (Bogdanov, 1997). The analysis was performed in duplicate for each sample.

\section{Infrared Spectroscopy Measurements}

Spectral collections of honey samples were carried out using two different instruments as further described below:

Portable Fourier-Transformed Mid-Infrared (FT-IR) System

A Cary 630 FTIR spectrometer (Agilent Technologies Inc., Danbury, CT, USA) including a single-bounce ATR (Attenuated Total Reflectance), ZnSe beamsplitter and DTGS detector was used to analyze the honey samples. The spectra of the samples were collected over the frequency range $4000-700 \mathrm{~cm}^{-1}$ in the reflectance mode. Approximately $0.1 \mathrm{~g}$ of honey sample was placed on the surface of portable FTIR spectrometer's diamond ATR and spectra were collected with $4 \mathrm{~cm}^{-1}$ resolution. In order to improve the signal to noise ratio, 64 spectra were coadded. Additionally, the infrared spectra of background were collected prior to spectral collection of a sample and spectra of the sample only was recorded using Agilent MicroLab PC software (Agilent Technologies Inc., Danbury, CT, USA). After the collecting spectra, the crystal was cleaned and dried using $70 \%$ ethanol (v:v) and $100 \%$ cotton clothes. For each sample, two independent spectral measurements were taken.

\section{Handheld Near Infrared (NIR) System}

A dispersive handheld NIR system (microPhazir, Thermo Fisher Scientific Inc., Wilmington, MA, USA) was used to collect the NIR spectra of the honey samples. The device was equipped with a single Indium Gallium Arsenide (InGaAs) detector. About $1 \mathrm{~g}$ honey was filled in a capped glass vial (Pike Technologies, Madison, WI, USA). Before collecting spectra of the sample, the background spectrum was collected using internal gold reference material. Spectra were collected using an optical resolution of $11 \mathrm{~nm}$, between 1600 and $2400 \mathrm{~nm}(6250$ $4170 \mathrm{~cm}^{-1}$ ). Similar to portable FTIR unit, 64 scans were collected and averaged to increase the signal to noise ratio.

\section{Multivariate Data Analysis}

For multivariate analysis of the spectra, Pirouette software (version 4.0, Infometrix Inc., Woodville, WA, USA) was used. Quantitative models for each of 10 parameters in honey samples were generated with Partial Least Squares Regression (PLSR) using the infrared spectra and the values from the reference analyses (dependent variable). PLSR helps to avoid overfitting during model development (Haaland and Thomas, 1988) by extracting and using the "latent variables (PLSfactors)" important to explain the variation in the model (usually less than 10) instead of thousands of wavenumbers (Moseholm, 1988). PLSR has become popular in both academic and industrial works. For internal and external validation of the models, full crossvalidation (leave-one-out approach) and an independent sample set were used, respectively. For external calibration of the models, honey samples $(n=59)$ were randomly divided into two groups as calibration $(n=47)$ and validation $(n=12)$ sets. Splitting the samples into calibration and independent validation sets were done with the condition that both duplicates belonging to the same honey sample could only be a part calibration or validation set. Additional parameters including loading vectors, standard error of cross validation (SECV), standard error of prediction (SEP), correlation coefficient (r) and outlier diagnostics (Standard Residual of Sample vs. leverage), Residual Predictive Deviation (RPD) values were also calculated and used during the model development. RPD is known as the ratio of standard deviation of the reference results in the validation set to SEP. The criteria for RPD levels adopted from Saeys et al. (2005) who reported different levels of RPD classification, with RPD values above 2.5 and 3.0 indicating that models were classified as good and excellent, respectively. However, models with an RPD value below 1.5 was considered as very poor models. During the model development, if samples with abnormal standard residual $(>2)$ and high leverage were observed, IR spectra of those samples were collected again and reanalyzed. If this did not solve the problem, those samples were considered as outliers, excluded from the model and the model was repeated.

\section{Results and Discussion}

\section{Reference Analyses}

Reference results obtained using traditional methods for honey samples are summarized in Table 1. Sucrose concentrations of the samples ranged between 29.2 and $156.5 \mathrm{~g} / \mathrm{kg}$, averaging at $54.4 \mathrm{~g} / \mathrm{kg}$ honey. According to European Union standards, sucrose levels should be a maximum of $5 \%$ in general and $10 \%$ for honeydew honey or blends of honeydew honey and blossom honey (Bogdanov, 1997). Although the average of the samples were close to the threshold of 5\% (5.44\%), some of the samples contained higher concentrations of sucrose up to $15.7 \%$. These higher values could be due either to impaired inversion process, or the bees were fed with sucrose syrups or economic adulteration by addition of 
sucrose to the honey. Glucose levels in the samples ranged between 183.8 and $317.6 \mathrm{~g} / \mathrm{kg}$, with an average of $273.5 \mathrm{~g} / \mathrm{kg}$ honey while fructose levels were between 264.8 and $426.4 \mathrm{~g} / \mathrm{kg}$ with an average of $356.4 \mathrm{~g} / \mathrm{kg}$ honey. Overall, fructose had the highest content among the sugars analyzed as previously reported. Although sugar levels vary depending on nectar type and regional climatic conditions, the results were in accordance with the fact that the products of sucrose hydrolysis (glucose and fructose) are reported to make up about $85-95 \%$ of total carbohydrate content of honey (approximately $38.5 \mathrm{~g}$ fructose and $31 \mathrm{~g}$ glucose per $100 \mathrm{~g}$ honey) (Cozzolino et al., 2011). Reducing sugar content calculated as sum of glucose and fructose level was also reported for the samples as ranging between 452.2 and $704.9 \mathrm{~g} / \mathrm{kg}$, averaging at $629.9 \mathrm{~g} / \mathrm{kg}$ honey. According to European Union standards (Bogdanov, 1997), reducing sugar level should not be less than $600 \mathrm{~g} / \mathrm{kg}$ honey for blossom and $450 \mathrm{~g} / \mathrm{kg}$ honey for honeydew and its blend with blossom honey.

The detection of 5-HMF is very important since 5HMF level in honey depends on not only the time and degree of heat treatment but also storage condition and chemical properties of honey (Zappala et al., 2005). The amount of 5-HMF, a product of Maillard reaction and a breakdown product of fructose, must be lower than 40 $\mathrm{mg} / \mathrm{kg}$ according to Codex Alimentarius and European Union standards (Cozzolino et al., 2011). The concern of 5-HMF is due to its hazardous health effects as being genotoxic, cytotoxic (Nässberger, 1990), carcinogenic and mutagenic (Janzowski et al., 2000). 5-HMF levels in the samples were found to be between 29.4 and $150.6 \mathrm{mg} / \mathrm{kg}$ with an average of $54.3 \mathrm{mg} / \mathrm{kg}$ honey and some samples exceeded the recommended standard limits indicating a possible process or storage abuse. The results were similar to other reported studies in honeys from Australia (50.8 to $74.9 \mathrm{mg} / \mathrm{kg}$ ) (Ajlouni and Sujirapinyokul, 2010), Morocco (0.09 to $53.4 \mathrm{mg} / \mathrm{kg}$ ) (Chakir et al., 2011), Portugal (1.75 to $32.8 \mathrm{mg} / \mathrm{kg}$ ) (Silva et al., 2009) and Switzerland (0.00-112 mg/kg) (Ruoff et al., 2007).

The levels of total soluble solids ( $\left.{ }^{\circ} \mathrm{Brix}\right)$ values ranged between 77.2 and 87.3 and the mean value was 82.0 . The results were similar to ${ }^{\circ}$ Brix levels reported for the Lusa region of Portuguese and Spanish honeys with reported ranges of 79.0 to 82.2 (Silva et al., 2009) and 78.8 to 84.0 (Terrab et al., 2004), respectively. Refractive index of the samples was found to range between 1.49-1.51. The refractive index (RI) is a measurement for the amount of refraction characteristic for every substance that can be used for detection of moisture content in honey by using a conversion table (Wedmore's table, AOAC, 1996). Determination of moisture content in honey is important since it influences not only the color and flavor but also the shelf life of the honey. Undesirable fermentation can occur in honey with a water level above $18 \mathrm{~g}$ water / 100 $\mathrm{g}$ honey (Ruoff et al., 2006a). Moisture content in the samples varied between 13.0 and $20.0 \%$, with the mean value of $16.0 \%$, which were below the maximum moisture content for honey of $20 \%$ established by the Codex Alimentarius (1993). Similar levels of moisture content have been reported in previous studies (Finola et al., 2007; Bera et al., 2009; Alemu et al., 2013; Oroian, 2015).

Water activity level of honey is crucial for its quality in terms of not only fermentation caused by osmophilic yeasts growth in honey (Gleiter et al., 2006) but also for crystallization of honey. The mean $\mathrm{a}_{\mathrm{w}}$ and range of honey samples were between 0.56 and 0.47-0.64, respectively. Mean result for water activity was below the critical value for osmophilic yeast growth as low as 0.61 (Zamora and Chirife, 2006) ensuring a relatively long shelf life of the honey samples. The results were in line with the mean values of Italian (0.593) (Venir et al., 2010) and Argentinan (0.562) honeys (Zamora and Chirife, 2006).

Honey naturally has low $\mathrm{pH}$ values affecting the honey extraction process, texture and shelf-life (Terrab et al., 2002). The $\mathrm{pH}$ values of the honey samples ranged between 3.52 and 4.66 with a mean $\mathrm{pH}$ value of 3.83 . $\mathrm{pH}$ values were consistent with similar studies conducted on Brazilian (3.10-4.05) (da C Azeredo et al., 2003), Nigerian (4.31-6.02) (Adebiyi et al., 2004), Indian (3.704.40) (Saxena et al., 2010), Algerian (3.70-4.00) (Khalil et al., 2012) and Portuguese (3.18-4.10) (Gomes et al., 2010) honeys.

Table 1 Reference results obtained using traditional methods for the parameters of interest in 59 honey samples used in this study

\begin{tabular}{l|cccc}
\hline \multicolumn{1}{c|}{ Parameter } & Minimum & Maximum & Mean & Standard Deviation \\
\hline Sucrose $(\mathrm{g} / \mathrm{kg})$ & 29.2 & 156.5 & 54.4 & 20.1 \\
Glucose $(\mathrm{g} / \mathrm{kg})$ & 183.8 & 317.6 & 273.5 & 32.3 \\
Fructose (g/kg) & 264.8 & 426.4 & 356.4 & 29.6 \\
Reducing Sugar ${ }^{*}(\mathrm{~g} / \mathrm{kg})$ & 452.2 & 704.9 & 629.9 & 1.6 \\
5 -HMF (mg/kg) & 29.4 & 150.6 & 54.3 & 1.70 \\
Brix & 77.2 & 87.3 & 82.0 & 1.3 \\
Moisture (\%) & 13.0 & 20.0 & 16.0 & 0.03 \\
Water Activity & 0.47 & 0.64 & 0.56 & 0.32 \\
pH & 3.37 & 4.68 & 3.81 & 5.93 \\
Free Acidity (meq/kg) & 9.57 & 32.6 & 21.0 & \\
\hline
\end{tabular}

\footnotetext{
Sum of glucose and fructose concentrations
} 
Table 2 Comparison of some statistical parameters of the sample sets used to develop calibration and prediction models in honey samples using portable FTIR and handheld NIR

\begin{tabular}{|c|c|c|c|c|c|c|}
\hline Parameter & Sample Set & $\mathrm{NS}^{\mathrm{b}}$ & Minimum & Maximum & Mean & SD \\
\hline \multirow{2}{*}{ Sucrose $(\mathrm{g} / \mathrm{kg})$} & Calibration & $44-43$ & $30.4-30.4$ & $79.2-79.2$ & $51.9-52.3$ & $12.6-12.3$ \\
\hline & Validation & $12-12$ & $40.3-40.3$ & $75.9-75.9$ & $49.3-50.8$ & $10.7-11.5$ \\
\hline \multirow{2}{*}{ Glucose $(\mathrm{g} / \mathrm{kg})$} & Calibration & $47-45$ & $185-185$ & $317-317$ & $274-275$ & $32.4-32.9$ \\
\hline & Validation & $12-12$ & $208-193$ & $302-298$ & $270-268$ & $27.3-27.8$ \\
\hline \multirow{2}{*}{ Fructose $(\mathrm{g} / \mathrm{kg})$} & Calibration & $47-47$ & $269-269$ & $424-424$ & $355-355$ & $29.0-29.4$ \\
\hline & Validation & $12-12$ & $299-299$ & $405-405$ & $364-362$ & $29.0-29.2$ \\
\hline \multirow{2}{*}{ Reducing Sugar ${ }^{\mathrm{a}}(\mathrm{g} / \mathrm{kg})$} & Calibration & $47-45$ & $469-469$ & $691-689$ & $627-628$ & $55.1-54.4$ \\
\hline & Validation & $12-11$ & $552-552$ & $684-684$ & $642-641$ & $35.1-36.7$ \\
\hline \multirow{2}{*}{ 5-HMF (mg/kg) } & Calibration & $41-42$ & $29.4-29.4$ & $79.2-79.2$ & $50.6-51.6$ & $13.3-13.7$ \\
\hline & Validation & $12-12$ & $40.3-40.3$ & $75.9-75.9$ & $49.6-50.7$ & $10.6-11.0$ \\
\hline \multirow{2}{*}{ Brix $^{o}$} & Calibration & $45-44$ & $77.8-77.8$ & $87.3-87.3$ & $82.0-81.9$ & $1.70-1.69$ \\
\hline & Validation & $12-12$ & $79.8-79.8$ & $83.2-83.2$ & $81.6-81.6$ & $1.10-1.05$ \\
\hline \multirow{2}{*}{ Moisture (\%) } & Calibration & $45-45$ & $13.0-13.7$ & $19.5-20.0$ & $16.2-16.2$ & $1.10-1.24$ \\
\hline & Validation & $12-12$ & $14.6-13.8$ & $17.6-17.6$ & $16.3-15.9$ & $0.80-1.08$ \\
\hline \multirow{2}{*}{ Water Activity } & Calibration & $43-45$ & $0.47-0.47$ & $0.63-0.63$ & $0.57-0.57$ & $0.03-0.03$ \\
\hline & Validation & $12-12$ & $0.54-0.54$ & $0.59-0.59$ & $0.57-0.56$ & $0.02-0.02$ \\
\hline \multirow{2}{*}{$\mathrm{pH}$} & Calibration & $44-40$ & $3.52-3.52$ & $4.75-4.51$ & $3.77-3.70$ & $0.31-0.20$ \\
\hline & Validation & $12-12$ & $3.54-3.53$ & $4.25-4.21$ & $3.69-3.70$ & $0.20-0.20$ \\
\hline \multirow{2}{*}{ Free Acidity (meq/kg) } & Calibration & $43-41$ & $9.57-9.57$ & $32.6-29.6$ & $20.9-19.5$ & $5.91-5.00$ \\
\hline & Validation & $12-10$ & $10.4-18.4$ & $29.8-28.8$ & $22.7-23.5$ & $5.66-3.91$ \\
\hline
\end{tabular}
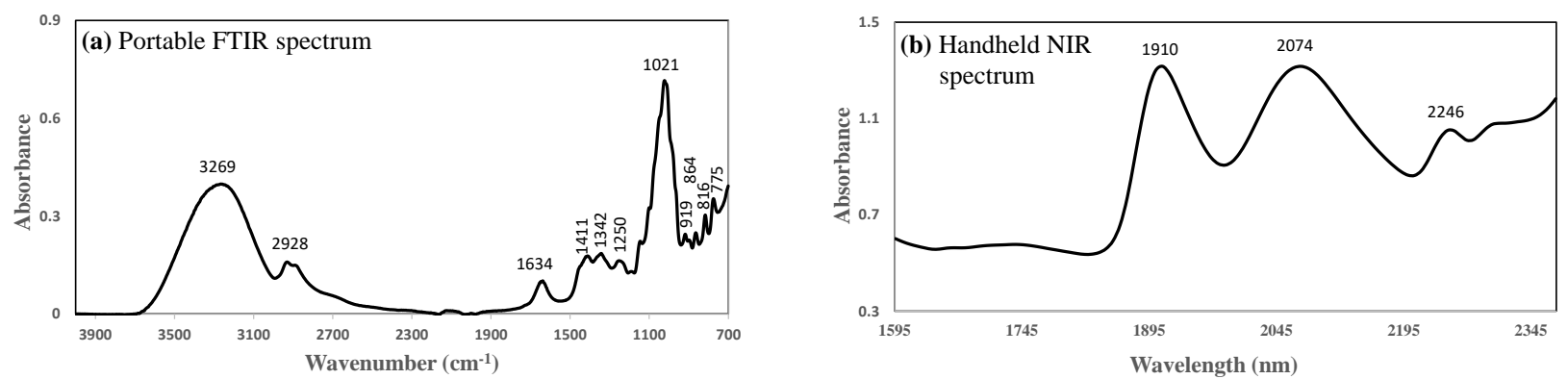

Figure 1 Representative spectra of honey samples collected using (a) portable FTIR and (b) dispersive handheld NIR spectrophotometers with major bands highlighted

Acidity value gives information about the fermentation status of the honey (Ruoff et al., 2006b) and affects flavors, microbial development, chemical reaction and antioxidant activities. Samples had a mean value of free acidity of $21.0 \mathrm{meq} / \mathrm{kg}$, ranging from 9.57 to 32.6 $\mathrm{meq} / \mathrm{kg}$, which were within the limits of $50 \mathrm{meq} / \mathrm{kg}$ established by the Codex Allimentarius (2001).

\section{IR Spectra}

Representative spectra of honey samples collected using portable FTIR and handheld NIR spectrometers are shown in Figure 1a and Figure 1b, respectively. In Figure 1a, major bands in the spectral region from 4000 to 700 $\mathrm{cm}^{-1}$ are highlighted. The bands centered at 3269 and $1634 \mathrm{~cm}^{-1}$ were related to water and corresponded to $\mathrm{O}-\mathrm{H}$ stretch and $\mathrm{O}-\mathrm{H}$ deformation, respectively. The band at $2928 \mathrm{~cm}^{-1}$ was attributed to the $\mathrm{C}-\mathrm{H}$ stretching of carboxylic acid and $\mathrm{NH}_{3}$ stretching band of free amino acids (Anjos et al., 2015). The region from 1450 to 750 $\mathrm{cm}^{-1}$ was the most informative region for honey constituents except for moisture content, water activity and $\mathrm{pH}$. The band at $919 \mathrm{~cm}^{-1}$ corresponded to the $\mathrm{C}-\mathrm{H}$ bending of the carbohydrates, the bands at 1021 and 1250 $\mathrm{cm}^{-1}$ corresponded to the $\mathrm{C}-\mathrm{O}$ stretch in the $\mathrm{C}-\mathrm{OH}$ group and $\mathrm{C}-\mathrm{C}$ stretch in the carbohydrate structure, respectively (Anjos et al., 2015). The small bands at 1342 and 1411 $\mathrm{cm}^{-1}$ were due to $\mathrm{O}-\mathrm{H}$ bending of the $\mathrm{C}-\mathrm{OH}$ group and combination of $\mathrm{O}-\mathrm{H}$ bending of the $\mathrm{C}-\mathrm{OH}$ group and $\mathrm{C}-\mathrm{H}$ bending of the alkenes (Anjos et al., 2015). Further information on band assignment of infrared vibrations of honey can be found elsewhere (Gok et al., 2015). In Figure 1b, the major bands highlighted at $1910 \mathrm{~nm}$ was attributed to $\mathrm{O}-\mathrm{H}$ stretch and bend vibrations and the band at $2074 \mathrm{~nm}$ was attributed to O-H deformation and C-O stretch vibrations (Osborne et al., 1993). The band centered at $2246 \mathrm{~nm}$ corresponded to combination of $\mathrm{C}-\mathrm{H}$ stretch and deformation modes (Osborne et al., 1993). 
Table 3 Prediction performance summary of PLSR models

\begin{tabular}{|c|c|c|c|c|c|c|c|c|c|}
\hline Parameter & I & MTU & Region used $^{b}$ & $\overline{F^{c}}$ & $\mathrm{SECV}^{\mathrm{d}}$ & $\mathrm{r}_{\mathrm{CV}}{ }^{\mathrm{e}}$ & SEP $^{f}$ & $\mathrm{r}_{\text {Pred }}{ }^{\mathrm{g}}$ & $\mathrm{RPD}^{\mathrm{h}}$ \\
\hline Sucrose & $\mathrm{PF}$ & Smooth (35) & $1239-842 \mathrm{~cm}^{-1}$ & 5 & 3.32 & 0.97 & 3.00 & 0.97 & 3.6 \\
\hline$(\mathrm{g} / \mathrm{kg})$ & $\mathrm{HN}$ & SNV & $2098-2374 \mathrm{~nm}$ & 7 & 5.48 & 0.90 & 6.22 & 0.86 & 1.8 \\
\hline Glucose & $\mathrm{PF}$ & Normalize (100) & $1200-1040 \mathrm{~cm}^{-1}$ & 3 & 13.5 & 0.91 & 9.02 & 0.95 & 3.0 \\
\hline$(\mathrm{g} / \mathrm{kg})$ & $\mathrm{HN}$ & SNV & $2001-2374 \mathrm{~nm}$ & 8 & 12.5 & 0.92 & 10.9 & 0.92 & 2.6 \\
\hline Fructose & $\mathrm{PF}$ & Smooth (35) & $1021-900 \mathrm{~cm}^{-1}$ & 6 & 12.2 & 0.93 & 11.2 & 0.93 & 2.6 \\
\hline$(\mathrm{g} / \mathrm{kg})$ & $\mathrm{HN}$ & SNV & $2200-2374 \mathrm{~nm}$ & 5 & 11.1 & 0.93 & 11.8 & 0.93 & 2.5 \\
\hline Reducing & $\mathrm{PF}$ & Smooth (35) & $1200-900 \mathrm{~cm}^{-1}$ & 6 & 18.7 & 0.94 & 16.2 & 0.90 & 2.2 \\
\hline $\operatorname{Sugar}^{\mathrm{a}}(\mathrm{g} / \mathrm{kg})$ & $\mathrm{HN}$ & SNV & $2033-2299 \mathrm{~nm}$ & 5 & 19.4 & 0.93 & 18.7 & 0.88 & 2.0 \\
\hline $5-\mathrm{HMF}$ & $\mathrm{PF}$ & Smooth (35) & $1226-751 \mathrm{~cm}^{-1}$ & 5 & 4.44 & 0.94 & 3.03 & 0.97 & 3.5 \\
\hline$(\mathrm{mg} / \mathrm{kg})$ & $\mathrm{HN}$ & SNV & $1595-2374 \mathrm{~nm}$ & 7 & 5.35 & 0.92 & 5.00 & 0.93 & 2.2 \\
\hline Privo & $\mathrm{PF}$ & Smooth (35) & $1083-866 \mathrm{~cm}^{-1}$ & 6 & 0.74 & 0.91 & 0.64 & 0.88 & 1.6 \\
\hline $\operatorname{Brix}^{\circ}$ & $\mathrm{HN}$ & SNV & $1993-2374 \mathrm{~nm}$ & 4 & 0.63 & 0.93 & 0.40 & 0.97 & 2.6 \\
\hline \multirow{2}{*}{ Moisture (\%) } & $\mathrm{PF}$ & Smooth (35) & $3696-2902+1780-1420 \mathrm{~cm}^{-1}$ & 4 & 0.63 & 0.83 & 0.47 & 0.85 & 1.8 \\
\hline & $\mathrm{HN}$ & SNV & $1595-2374 \mathrm{~nm}$ & 6 & 0.29 & 0.97 & 0.28 & 0.97 & 3.9 \\
\hline Water & $\mathrm{PF}$ & Divide by + Smooth $(35)$ & $1735-773 \mathrm{~cm}^{-1}$ & 4 & 0.02 & 0.90 & 0.01 & 0.91 & 1.8 \\
\hline Activity & $\mathrm{HN}$ & Divide by & $1810-2017 \mathrm{~nm}$ & 5 & 0.02 & 0.85 & 0.01 & 0.94 & 2.7 \\
\hline \multirow{2}{*}{$\mathrm{pH}$} & $\mathrm{PF}$ & Divide by + Smooth (35) & $1780-1519 \mathrm{~cm}^{-1}$ & 4 & 0.07 & 0.97 & 0.07 & 0.94 & 2.9 \\
\hline & $\mathrm{HN}$ & Divide by & $1595-2374 \mathrm{~nm}$ & 6 & 0.09 & 0.88 & 0.07 & 0.93 & 2.7 \\
\hline \multirow{2}{*}{$\begin{array}{l}\text { Free Acidity } \\
(\mathrm{meq} / \mathrm{kg})\end{array}$} & $\mathrm{PF}$ & Divide by + Smooth $(35)$ & $1800-1692+1314-1133 \mathrm{~cm}^{-1}$ & 7 & 2.24 & 0.92 & 2.42 & 0.90 & 2.3 \\
\hline & $\mathrm{HN}$ & Divide by & $1793-2299 \mathrm{~nm}$ & 6 & 3.83 & 0.64 & 3.80 & 0.67 & 1.0 \\
\hline
\end{tabular}

I: Instrument, PF: Portable FTIR, HN: Handheld NIR, MTU: Math Treatments used, ${ }^{\mathbf{a}}$ Sum of glucose and fructose concentrations, ${ }^{\mathbf{b}}$ The part of the IR region used for the model ("cm" ${ }^{-1}$ " was used for Fourier transformed MIR system, "nm" was used for dispersive NIR system), ${ }^{\text {c }}$ F: Factors, set of orthogonal factors that account for most of the variation in the response, ${ }^{\mathrm{d}} \mathrm{SECV}$ : standard error of cross-validation leave-1 out, ${ }^{\mathbf{e}}$ rCV: correlation coefficient of cross-validation leave-1-out, ${ }^{\mathbf{f}}$ SEP: standard error of prediction, ${ }^{\mathrm{g}}$ rPred: correlation coefficient of prediction for the validation set, ${ }^{\mathbf{h}}$ RPD (Residual Predictive Deviation). It is calculated as [Standard Deviation of Reference Data / Standard Error of Prediction]

(a)

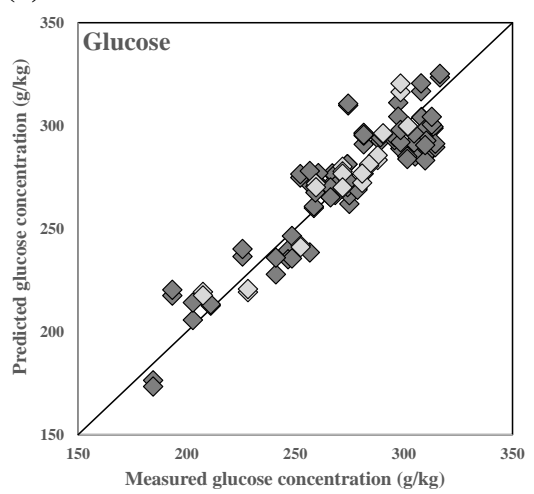

(d)

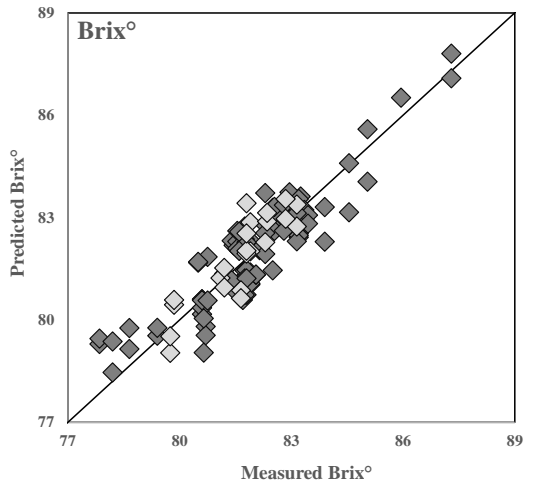

(b)

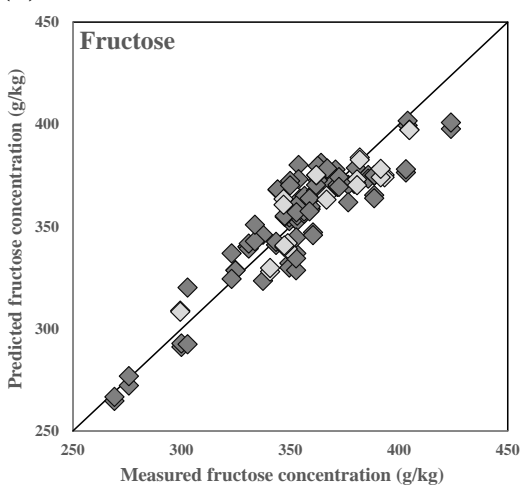

(e)

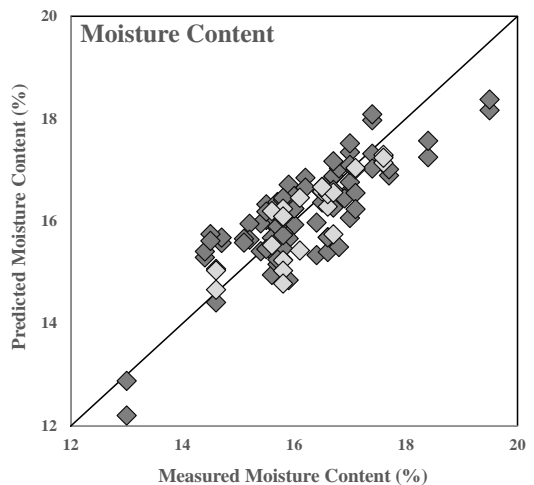

(c)

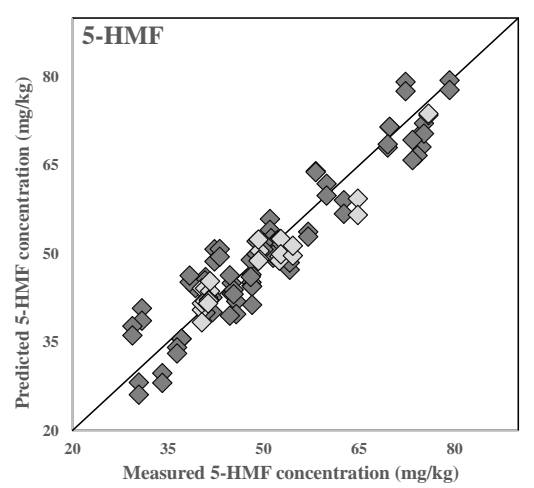

(f)

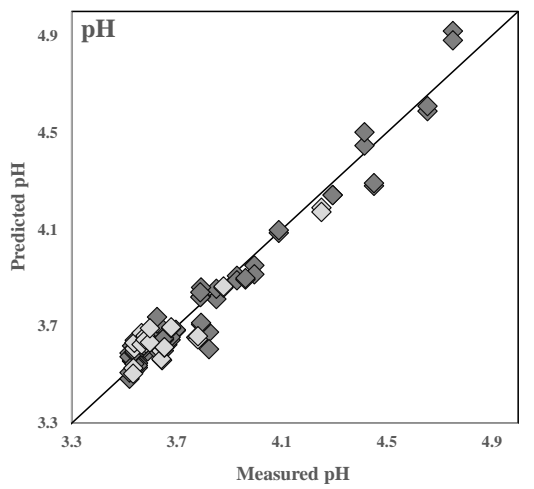

Figure 2 PLSR correlation plots for estimating (a) glucose $(\mathrm{g} / \mathrm{kg}),(\mathbf{b})$ fructose $(\mathrm{g} / \mathrm{kg}),(\mathbf{c}) \mathrm{HMF}(\mathrm{mg} / \mathrm{kg}),(\mathbf{d}) \mathbf{b r i x}{ }^{\circ},(\mathbf{e})$ moisture content $(\%)$, (f) $\mathrm{pH}$ using portable FTIR unit $(>$ and $r$ represent calibration and validation set samples, respectively) 
(a)

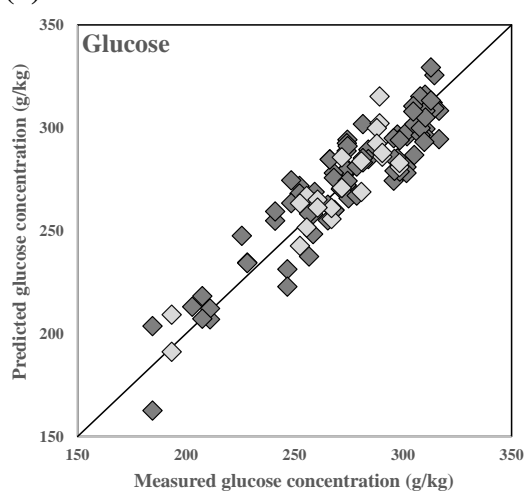

(d)

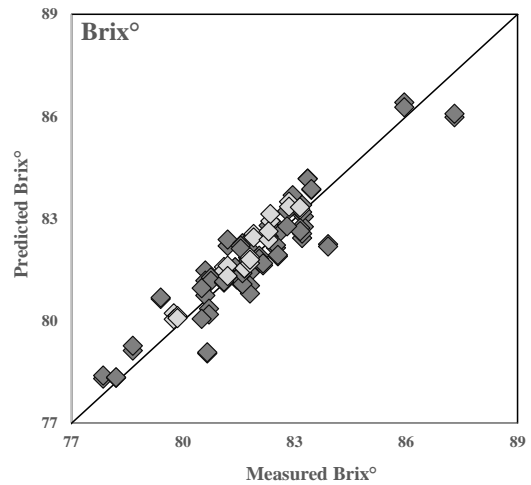

(b)

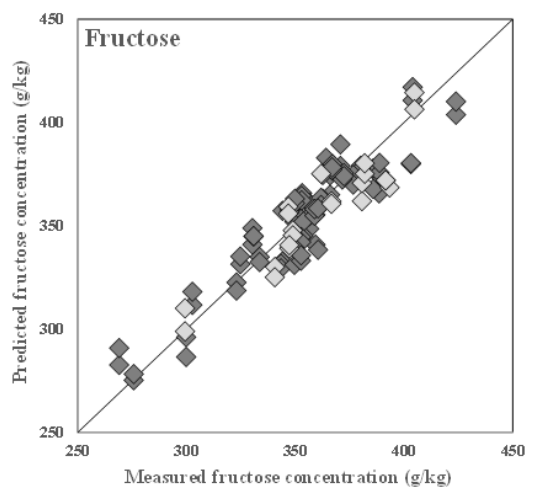

(e)

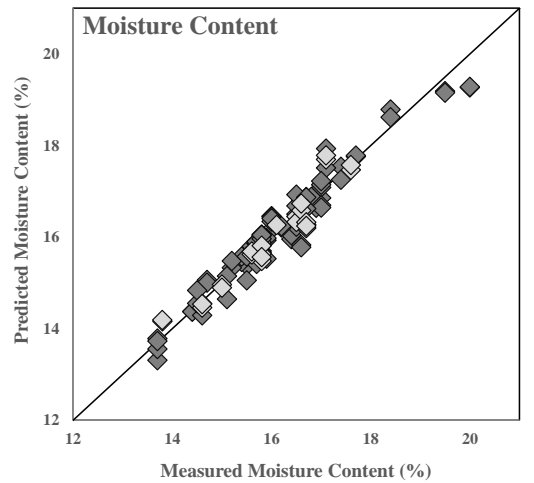

(c)

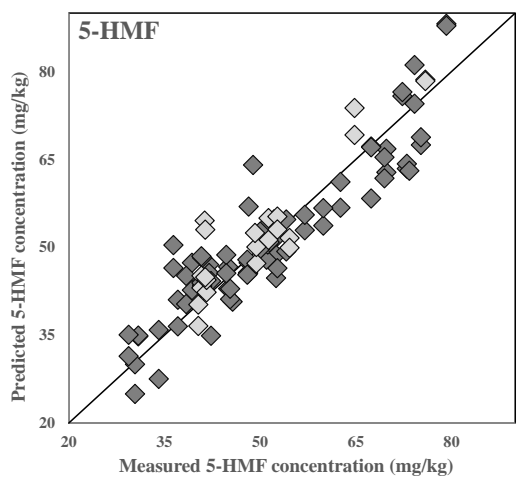

(f)

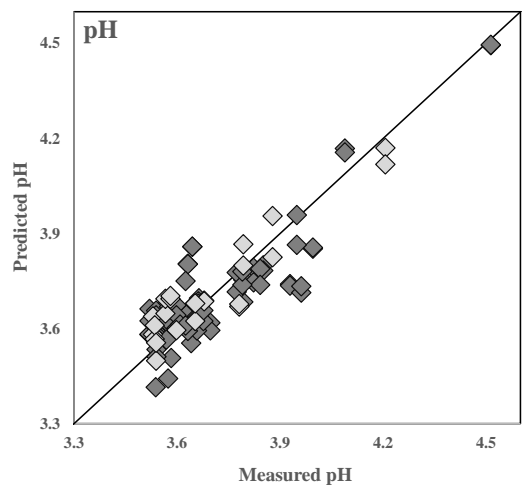

Figure 3 PLSR correlation plots for estimating (a) glucose $(\mathrm{g} / \mathrm{kg}),(\mathbf{b})$ fructose $(\mathrm{g} / \mathrm{kg}),(\mathbf{c}) \mathrm{HMF}(\mathrm{mg} / \mathrm{kg}),(\mathbf{d}) \mathrm{brix}{ }^{\circ},(\mathbf{e})$ moisture content (\%), (f) $\mathrm{pH}$ using dispersive handheld NIR $(>$ and $>$ represent calibration and validation set samples, respectively)

\section{PLSR Model Development}

Number of samples, minimum and maximum values, mean and standard deviations for calibration and validation sets for each quality parameter for portable FTIR and handheld NIR spectrometers are shown in Table 2. Overall, the mean and ranges of values for calibration and validation groups within the same quality parameter were very similar. Differences in the total number of samples (calibration + validation) from $n=59$ were due to removal of outliers (samples with high leverage and residuals) identified during the model development process.

Table 3 shows the performance statistics of the PLSR models developed for each quality trait using portable FTIR and handheld NIR systems. The infrared regions used in developing the PLSR model were optimized for each analyte, except for 5-HMF, moisture content and $\mathrm{pH}$ that utilized the complete spectral range available (1595$2374 \mathrm{~nm}$ ) for the handheld NIR. Choosing spectral specific regions eliminated irrelevant, noisy and unreliable data and therefore improved the predictions (Leardi and Nørgaard, 2004). Overall, similar number of factors were used for portable FTIR and handheld NIR data to develop the models except for glucose, where only 3 factors were required for portable FTIR while 8 factors were needed for handheld NIR. The accuracy of the predictions may improve with the increase in the number of factors incorporated in the calibration models. Nevertheless, this may cause to the addition of random noise in the model, leading to what is called "overfitting" (Hawkins, 2004). Adversely, the use of too few factors may cause the relevant variation within the data set to be omitted, which is known as "underfitting" (Naes et al., 1986).

$\mathrm{R}_{\mathrm{CV}}$ and $\mathrm{r}_{\text {Pred }}$ values are expected to be close to 1 and values above 0.8 are considered good for accurate prediction of the variables (Zhang et al., 2014). Table 3 shows correlation coefficient of cross-validation $\left(\mathrm{r}_{\mathrm{CV}}\right)$ values for all calibration models ranged between 0.83 and 0.97 except for the free acidity model developed by using the handheld NIR, which yielded a low $r_{C V}$ value of 0.64 . Performance statistics of PLSR models for crossvalidation (SECV and $r_{C V}$ ) and validation (SEP and $r_{v a l}$ ) for the same parameter were similar, which indicated that the models were reliable and robust in predictions (Nicolai et al., 2007). Visualization of the good correlations between reference measured and infrared predicted levels in honey samples can be observed for selected quality attributes for portable FTIR (Figure 2) and handheld NIR (Figure 3). Representative dispersion of data points for validations sets within the range of calibration set was observed in all the plots (Figure 2 and Figure 3).

Based on the standard errors obtained in the external validations as shown in Table 3, both devices performed similarly for most of the parameters, except with the major differences observed in sucrose, 5-HMF, ${ }^{\circ}$ Brix, 
moisture and free acidity models. Among these models, portable FTIR gave much better statistics for sucrose (SEP of $3.00 \mathrm{~g} / \mathrm{kg}$ vs $6.22 \mathrm{~g} / \mathrm{kg}$, due to the presence of better resolved bands associated with sucrose in Mid-IR region), $5-\mathrm{HMF}(3.03 \mathrm{mg} / \mathrm{kg}$ vs $5.00 \mathrm{mg} / \mathrm{kg}$ ) and free acidity $(2.42 \mathrm{meq} / \mathrm{kg}$ vs $3.80 \mathrm{meq} / \mathrm{kg})$ compared to the handheld NIR unit. On the other hand, handheld NIR showed better performance for the parameters of ${ }^{\circ}$ Brix and moisture content. SEP values of handheld NIR and portable FTIR systems for the ${ }^{\circ}$ Brix were 0.40 and 0.64 , respectively. The handheld NIR device outperformed the portable FTIR in models predicting moisture content, most likely due to the presence of broader band related to moisture in NIR region. As opposed to SEP of $0.47 \%$ and RPD value of only 1.8 obtained with portable FTIR system, handheld NIR model gave an SEP of $0.28 \%$ and RPD value of 3.9. For other parameters (glucose, fructose, reducing sugars, $\mathrm{pH}$ and $\mathrm{a}_{\mathrm{w}}$ ), the performances of both systems were quite similar in terms of SEP values. According to RPD values calculated for the models, both system generally led to "good" and "excellent models" except for the ${ }^{\circ}$ Brix, moisture and $a_{w}$ for portable FTIR and sucrose and free acidity for handheld NIR, for which the predictive performance of the models were lower than the expected.

In this study, the composition characteristics (sucrose, glucose, fructose, reducing sugar, 5-HMF, ${ }^{\circ}$ Brix, moisture content, water activity, $\mathrm{pH}$ and free acidity) of 59 honey samples collected from different regions of Turkey were studied using traditional methods. The samples gave wide range of concentrations for each parameter, being mostly within the limits according to commonly used standards. However, the levels of sucrose and 5-HMF were over the established regulatory limits, indicating that some of the samples could be possibly adulterated and exposed process or storage abuse. Moisture content, aw, $\mathrm{pH}$ and free acidity values of the samples did not support the undesired microbial growth and fermentation. Although both systems performed similarly, portable FTIR system was superior in predictions of sucrose, 5-HMF and free acidity while handheld NIR system performed better for ${ }^{\circ}$ Brix and moisture content predictions. Free acidity model of handheld NIR system was poor. The data indicates that all of the 10 parameters can be measured using both systems rapidly within the minutes (only sample preparation is the liquefying the honey in a water bath prior to spectral collection) so that the possible use of large volumes of solvents, other chemicals and such, which are required in traditional methods, can be avoided. New generation handheld and portable systems provide fast, simple, cost-effective alternatives for monitoring quality attributes in honey samples requiring low sample volume and minimal operational costs involved on performing the test. Additional benefits of using portable and handheld systems includes the increased flexibility and the potential for in-field applications compared to bench-top systems which can only be used in a laboratory setting.

\section{References}

Adebiyi FM, Akpan I, Obiajunwa EI, Olaniyi HB. 2004. Chemical/physical characterization of Nigerian honey. Pak. J. Nutr., 3(5), 278-281.

Ajlouni S, Sujirapinyokul P. 2010. Hydroxymethylfurfuraldehyde and amylase contents in Australian honey. Food Chem., 119(3), 1000-1005.

Alemu T, Seifu E, Bezabih A. 2013. Physicochemical properties of honey produced in Sekota district, northern Ethiopia. Int. Food Res. J., 20(6), 3061-3067.

Anjos O, Campos MG, Ruiz PC, Antunes P. 2015. Application of FTIR-ATR spectroscopy to the quantification of sugar in honey. Food Chem., 169, 218-223.

AOAC. 1996. Official methods of analysis (16th ed.). Washington, DC: Association of Official Analytical Chemists. Methods: 969.38 B, 925.45.D, 920.181, 962.19 vol. II.

Arvanitoyannis IS, Chalhoub C, Gotsiou P, Lydakis-Simantiris N, Kefalas P. 2005. Novel quality control methods in conjunction with chemometrics (multivariate analysis) for detecting honey authenticity. Crit. Rev. Food Sci., 45(3), 193-203.

Ayvaz H, Rodriguez-Saona LE. 2015. Application of handheld and portable spectrometers for screening acrylamide content in commercial potato chips. Food Chem.174, 154-162.

Ayvaz H, Plans M, Towers BN, Auer A, Rodriguez-Saona LE. 2015a. The use of infrared spectrometers to predict quality parameters of cornmeal (corn grits) and differentiate between organic and conventional practices. J. Cereal Sci., 62, 22-30.

Ayvaz H, Santos AM, Moyseenko J, Kleinhenz M, RodriguezSaona LE. 2015b. Application of a Portable Infrared Instrument for Simultaneous Analysis of Sugars, Asparagine and Glutamine Levels in Raw Potato Tubers. Plant Food Hum. Nutr., 70(2), 215-220.

Ayvaz H, Bozdogan A, Giusti MM, Mortas M, Gomez R, Rodriguez-Saona LE. 2016a. Improving the screening of potato breeding lines for specific nutritional traits using portable midinfrared spectroscopy and multivariate analysis. Food Chem., 211, 374-382.

Ayvaz H, Sierra-Cadavid A, Aykas DP, Mulqueeney B, Sullivan S, Rodriguez-Saona LE. 2016b. Monitoring multicomponent quality traits in tomato juice using portable mid-infrared (MIR) spectroscopy and multivariate analysis. Food Control, 66, 79-86.

Bera A, Almeida-Muradian LB, Sabato SF. 2009. Effect of gamma radiation on honey quality control. Radiat. Phys. Chem., 78(7), 583-584.

Bhandari B, D'Arcy B, Chow S. 1999. Rheology of selected Australian honeys. J. Food Eng., 41(1), 65-68.

Bogdanov S, Baumann E. 1988. Bestimmung von Honigzucker mit HPLC. Mitt. Geb. Lebensmittelunters Hyg., 79, 198-206.

Bogdanov S, Martin P, Lüllmann C. 1997. Harmonised methods of the European Honey Commission, Apidologie, 28, 1-59.

Cabanero AI, Recio JL, Ruperez M. 2006. Liquid chromatography coupled to isotope ratio mass spectrometry: a new perspective on honey adulteration detection. J. Agr. Food Chem., 54(26), 9719-9727.

Chakir A, Romane A, Marcazzan GL, Ferrazzi P 2011. Physicochemical properties of some honeys produced from different plants in Morocco. Arabian J. Chem., (In press) http://dx.doi.org/10.1016/j.arabjc.2011.10.013

Codex Alimentarius Commission. 1993. Standard for honey. Ref. no. CL 1993/14, SH. Rome: Codex Alimentarius Commission FAO/WHO.

Codex Alimentarius Commission. 2001. Revised codex standard for honey. Codex Standard 12-1981. Rome: FAO and WHO.

Cozzolino D, Corbella E, Smyth HE. 2011. Quality control of honey using infrared spectroscopy: a review. Appl. Spectrosc. Rev., 46(7), 523-538.

da C Azeredo L, Azeredo MAA, De Souza SR, Dutra VML. 2003. Protein contents and physicochemical properties in honey samples of Apis mellifera of different floral origins. Food Chem., 80(2), 249-254. 
FAOSTAT. "FAOSTAT Agricultural Production Database". http://faostat3.fao.org/browse/Q/QL/E (Last accessed on 8th of November, 2016).

Finola MS, Lasagno MC, Marioli JM. 2007. Microbiological and chemical characterization of honeys from central Argentina. Food Chem., 100(4), 1649-1653.

Garcia-Alvarez M, Huidobro JF, Hermida M, Rodriguez-Otero JL. 2000. Major components of honey analysis by near-infrared transflectance spectroscopy. J. Agr. Food Chem., 48(11), 51545158.

Gleiter RA, Horn H, Isengard HD. 2006. Influence of type and state of crystallisation on the water activity of honey. Food Chem., 96(3), 441-445.

Gok S, Severcan M, Goormaghtigh E, Kandemir I, Severcan F. 2015. Differentiation of Anatolian honey samples from different botanical origins by ATR-FTIR spectroscopy using multivariate analysis. Food Chem., 170, 234-240.

Gomes S, Dias LG, Moreira LL, Rodrigues P, Estevinho L. 2010. Physicochemical, microbiological and antimicrobial properties of commercial honeys from Portugal. Food Chem. Toxicol., 48(2), 544-548.

Haaland DM, Thomas EV. 1988. Partial least-squares methods for spectral analyses. 1. Relation to other quantitative calibration methods and the extraction of qualitative information. Anal Chem., 60(11), 1193-1202.

Hawkins DM. 2004. The problem of overfitting. J. Chem. Inf. Comp. Sci., 44(1), 1-12.

Janzowski C, Glaab V, Samimi E, Schlatter J, Eisenbrand G. 2000. 5-Hydroxymethylfurfural: assessment of mutagenicity, DNAdamaging potential and reactivity towards cellular glutathione. Food Chem. Toxicol., 38(9), 801-809.

Jeuring HJ, Kuppers FJ. 1980. High performance liquid chromatography of furfural and hydroxymethylfurfural in spirits and honey. J. Assoc. Off. Anal. Chem., 63(6), 1215-1218.

Khalil I, Moniruzzaman M, Boukraâ L, Benhanifia M, Islam A, Islam N, Sulaiman SA, Gan SH. 2012. Physicochemical and Antioxidant Properties of Algerian Honey, Molecules, 17, 11199-11215.

Leardi R, Nørgaard L. 2004. Sequential application of backward interval partial least squares and genetic algorithms for the selection of relevant spectral regions. J. Chemometr., 18(11), 486-497.

Mendes E, Proenca EB, Ferreira IMPLVO, Ferreira MA. 1998. Quality evaluation of Portuguese honey. Carbohyd. Polym., 37(3), 219-223.

Moseholm L. 1988. Analysis of air pollution plant exposure data: the soft independent modelling of class analogy (SIMCA) and partial least squares modelling with latent variable (PLS) approaches. Environ. Pollut., 53(1-4), 313-331.

Naes T, Irgens C, Martens H. 1986. Comparison of linear statistical methods for calibration of NIR instruments. Appl. Stat-J Roy. St. C., 195-206.

Nässberger L. 1990. Influence of 5-hydroxymethylfurfural (5-HMF) on the overall metabolism of human blood cells. Hum. Exp. Toxicol., 9(4), 211-214.

Nicolai BM, Beullens K, Bobelyn E, Peirs A, Saeys W, Theron KI, Lammertyn J. 2007. Nondestructive measurement of fruit and vegetable quality by means of NIR spectroscopy: A review. J. Postharvest Biol. Tec., 46(2), 99-118.

Oroian M. 2015. Influence of temperature, frequency and moisture content on honey viscoelastic parameters-Neural networks and adaptive neuro-fuzzy inference system prediction. LWT-Food Sci. Technol., 63(2), 1309-1316.
Osborne BG, Fearn T, Hindle PH. 1993. Practical Near Infrared Spectroscopy with Applications in Food and Beverage Analysis (2nd edition). Harlow, U.K.: Longman Scientific \& Technical. pp:13-55.

Pujolras MP, Ayvaz H, Shotts ML, Pittman Jr RA, Herringshaw S, Rodriguez-Saona LE. 2015. Portable Infrared Spectrometer to Characterize and Differentiate Between Organic and Conventional Bovine Butter. J. Am. Oil Chem. Soc., 92(2), 175184.

Ruiz-Matute AI, Sanz ML, Martínez-Castro I. 2007. Use of gas chromatography-mass spectrometry for identification of a new disaccharide in honey. J. Chromatogr. A., 1157(1), 480-483.

Ruoff K, Luginbühl W, Bogdanov S, Bosset JO, Estermann B, Ziolko T, Amadò R. 2006a. Authentication of the botanical origin of honey by near-infrared spectroscopy. J. Agr. Food Chem., 54(18), 6867-6872.

Ruoff K, Iglesias MT, Luginbühl W, Bosset JO, Bogdanov S, Amadò R. 2006b. Quantitative analysis of physical and chemical measurands in honey by mid-infrared spectrometry. Eur. Food Res. Technol., 223(1), 22-29.

Ruoff K, Luginbühl W, Bogdanov S, Bosset JO, Estermann B, Ziolko T, Kheradmandan S, Amad R. 2007. Quantitative determination of physical and chemical measurands in honey by near-infrared spectrometry. Eur. Food Res. Technol., 225(3-4), 415-423.

Saeys W, Mouazen AM, Ramon H. 2005. Potential for onsite and online analysis of pig manure using visible and near infrared reflectance spectroscopy. Biosyst. Eng., 91(4), 393-402.

Saxena S, Gautam S, Sharma A. 2010. Physical, biochemical and antioxidant properties of some Indian honeys. Food Chem., 118(2), 391-397.

Silva LR, Videira R, Monteiro AP, Valentão P, Andrade PB 2009. Honey from Luso region (Portugal): Physicochemical characteristics and mineral contents. Microchem. J., 93(1), 7377.

Terrab A, Díez MJ, Heredia FJ. 2002. Characterisation of Moroccan unifloral honeys by their physicochemical characteristics. Food Chem., 79(3), 373-379.

Terrab A, Recamales A F, Hernanz D, Heredia FJ. 2004. Characterisation of Spanish thyme honeys by their physicochemical characteristics and mineral contents. Food Chem., 88(4), 537-542.

TUIK (Turkish Statistical Institute). "Istatistiksel Göstergeler". http://www.tuik.gov.tr/UstMenu.do?metod=temelist (Last accessed on 17th of March, 2017).

Venir E, Spaziani M, Maltini E. 2010. Crystallization in "Tarassaco" Italian honey studied by DSC. Food Chem., 122(2), 410-415.

White JW. 1975. Composition of honey. In: Crane E. Honey, A Comprehensive Survey. London, UK: Heinemann. pp:157-206.

Zábrodská B, Vorlová L. 2015. Adulteration of honey and available methods for detection-a review. Acta Vet. Brno, 83(10), 85102.

Zamora MC, Chirife J. 2006. Determination of water activity change due to crystallization in honeys from Argentina. Food Control, 17(1), 59-64.

Zhang L, Schultz MA, Cash R, Barrett DM, McCarthy MJ. 2014. Determination of quality parameters of tomato paste using guided microwave spectroscopy. Food Control, 40, 214-223.

Zappala M, Fallico B, Arena E, Verzera A. 2005. Methods for the determination of HMF in honey: a comparison. Food Control, 16(3), 273-277. 